\title{
ASSESSMENT OF MAJOR PHYSICAL STRESSORS AND ITS PSYCHOPHYSIOLOGY; A COMPREHENSIVE REVIEW
}

\author{
Syed Zain Azher ${ }^{l}$ Shamoon Noushad ${ }^{1} \&$ Sadaf Ahmed ${ }^{1 \& 2}$ \\ 1. Psychophysiology Research Division, Advance Educational Institute \& Research Centre \\ 2. Neurovascular Physiology \& Biophysics Unit, Department of Physiology, University of Karachi \\ Corresponding author: zain@ aeirc-edu.com
}

\begin{abstract}
The purpose of this review was to highlight the concept and understanding of physical stress and to discuss its Psychophysiological mechanisms along with characteristics and major causes. The environmental and physical changes that are responsible for alterations in the homeostasis of the body is simply identified as physical stress. The brain is to interpret experiences as alarming or non-alarming which trigger the physiological and behavioral responses in each situation. We gathered a literature data from different published articles, original research papers \& online sources. We hypothesized that the continuous imbalances of physiological mechanism due physical and environmental stimulus can cause physical stress and it is concluded that the major factors of physical stress includes injury, excessive exercise, noise, pregnancy, workload, pressures and temperature with the involvements of psycho-physiological mechanism.

KEYWORDS: Stress, Psychophysiology, Physical Stress, Stressors, Psychological, Physiological
\end{abstract}

\section{INTRODUCTION:}

Stress is a physical state of the brain and body that develops when physical stimuli affect the homeostasis (Sadaf, 2013), these situations or stimuli are considered as stress provoking are known as stressors (Stevens, 2013). It is known that if the stimulus disturbs the state of equilibrium, it could lead to structural or functional changes (Lazarus, 1986). Physical stress also defined as the force applied to a given area of biological tissue or is the response to environmental pressures and demands. Stress occurs when the demands upon an individual surpass the resources in body to meet such demands. Extrinsic factors are factors outside of the body that can influence either the level of stress on tissues or the thresholds for tissue adaptation and injury. However physical stress levels that exceed the maintenance range (i.e. overload) result in increased tolerance of tissues to subsequent stresses, so any exerted force that is characterized by vigorous bodily activity can lead to altered physiological responses is counted as physical stress (Syed, 2014). Moreover any exerted force that is characterized by vigorous bodily activity can lead to altered physiological responses is counted as physical stress such as aerobics, work outs, injury or aches. It may also count on physical traumas as cuts, burns, sprains, broken bones, surgery, etc. In other words physical stress is bodily response to substantial pressures such as exertion, noise, sickness or exercises (Sadaf, 2013). Excessive exercises, noise, are major physical stress stressors which change or disturb the body homeostasis. This comprehensive review is divided into two sections: (a) the Psychophysiology of stress, (b) to highlight the major physical stress stressors.

Stress affects the central nervous system leading indirectly to the modulation of the activity of steroid, catecholamine, peptide and opioid systems. It also affects other body systems: behavior, the immune system, cardiovascular responses and the gastrointestinal tract. In response to stress, a cascade of neurohumoral events chiefly at the level of the (hypothalamic-pituitary-adrenocortical) HPA axis, is triggered, the result of which is the termination of the stress reaction leading to normalization i.e. homeostasis (Miller, 2007).Temperature affects a broad spectrum of cellular components and metabolism, and temperature extremes impose stresses of variable severity that depend on the rate of temperature change, duration and intensity (Sung, 2003).moreover at the time of cell damage or injuries body start the process of coagulations which disturb the body homeostasis however excessive blood loss from a damaged vessel can lead to an increased risk of obstructive clotting thrombosis or bleeding hemorrhage (Desborough, 2000). Stressors effects may vary according to age and sex, individual variations play a major part in this respect in female at the time of pregnancy body feel constant physical stress due to changes of stress hormone, respiratory rate decreases excessive need of oxygen, increases blood pressure and increase insulin resistance which led to increase blood glucose level changes in body weight, total body water, plasma proteins, body fat, and cardiac output is seen (Anderson, 2005).During exercise Increase in the blood pressure, heart rate, vascular resistance and stress hormone levels are also observed and it also reported that weather high and low responders to exercise stress would show corresponding HPA reactivity to psychological stress. (Anita, 1999) Physical work load that sets high demands on muscle groups which cause back pain it is the main predictors of physical stress (Grant, 2006).

\section{Negative physical stress}

If any physical stressor triggers HPA axis for a long period of time and surge the stress hormonal level that cause tension and that may lead to illness, pain, feeling of unpleasant, anxiety decreases performance and overexertion is term as negative physical stress. Chronic physical stress that stays approximately for weeks or months it can weaken the immune system and cause high blood pressure, depression, fatigue and gastrointestinal problem and even heart diseases. In meticulous excessive epinephrine can be harmful to your heart.

\section{NEGATIVE PHYSICAL STRESS}

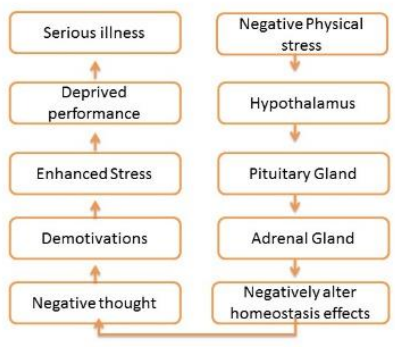

Page $\mid 3$

(CAdvance Education Institute \& Research Centre-2014 
Positive physical stress

If any physical stressor triggers HPA axis for a short period of time normally and provides enthusiasm and enjoyment, as well as consideration and energy for deadlines, exercising such as jogging or lifting weights entering new situations, motivation for new challenges and achieving maximum performance is term as positive physical stress. In addition, there are various health advantages with a little bit of physical stress. Researchers believe that some stress can help to make stronger the immune system. For example physical stress can get better your heart works and protect your body from infection. However individuals who experienced modest levels of stress prior to surgery were able to make progress faster than individuals who had low or high levels.

\section{POSITIVE PHYSICAL STRESS}

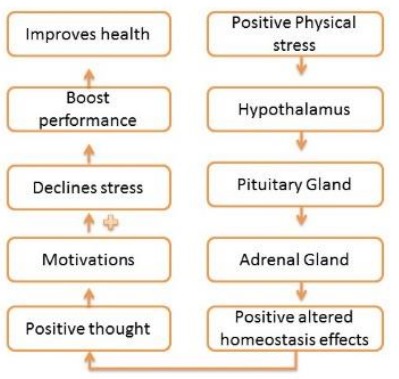

\section{PSYCHOPHYSIOLOGY OF PHYSICAL STRESS}

The fight or flight response named by Cannon and Selye in the 1930s is a pattern of physiological responses that prepare the organism to emergency. When the external balance is disputed our body changes its internal balance accordingly. The fact that modern problems do not require such means is exactly the setting of stress-related problems. The manifestations of the F or F are mainly through two channels: the sympathetic branch of the ANS and the Endocrine system both are closely interconnected The ANS effect many bodily functions instantly and directly, while hormones have slower yet wider effect on the body both hormones and neurones communicate with cells and create the delicate dynamic balance between the body and its surrounding, through paired systems and feedback mechanisms by acute and chronic pathway (See flow chart) (Ader, 1995; Miller, 2007). Increased heart rate, blood pressure and respiration and heart pump more blood to the muscles, supplying more oxygen to the muscles and heart and lung system. Allowing rapid energy use, and accelerating metabolism for emergency actions. Increased sugar rates in the blood. Thickening of the blood to increase oxygen supply, facilitate better defense from infections and to stop bleeding quickly, prioritizing - increased blood supply to peripheral muscles and heart, to motor and basic-functions regions in the brain; decreased blood supply to digestive system and irrelevant brain regions, this also causes secretion of body waists, leaving the body lighter. Secretion of adrenaline and other stress hormones to further increase the response and to strengthen relevant systems \& Secretion of endorphins is a natural painkiller, providing an instant defense against pain (Atkinson, 1996). The immune system protects the body with help of stress hormone; cortisol is

Page $\mid 4$

CAdvance Education Institute \& Research Centre-2014 responsible for interfering with the production the immune system components like leucocytes and antibodies. However aldosterone is another stress hormone that helps your body keep sodium which keeps more water in your blood, increasing blood pressure and volume. In chronic physical stress immune system is unable to respond to hormonal control, and consequently, produce levels of inflammation that promote disease such as cardiovascular, asthma and autoimmune disorders. Repeated firing of the hypothalamicpituitary-adrenal (HPA) axis and sympathetic nervous system (SNS) caused constant state of hypervigilance. This dysregulation can contribute to chronic diseases such as cardiovascular disease, Metabolic Syndrome, Autoimmune disease obesity, diabetes (Syed, 2013).

\section{PHYSICAL STRESS STRESSORS}

We try to highlight the major physical stressors in this review to explore or differentiate from other stress types.

\section{Noise:}

Noise is the most encountered stressor, produced by urban traffic, air craft's from work environment and house hold appliances. Long term experience to unavoidable noise stress induces exhaustion, defeat, annoyance followed by decreased muscle movement, social contacts and mood changes (Shankar, 1999).Noise affects the neurotransmitter levels in different regions of brain reduces dendritic count, elevates plasma corticosterone levels. It disrupts the activity or balance of life and causes psychological and physiological or behavioral changes in people. It has been reported to produce atrophy of dendrites and alterations in neurotransmitter levels. Even low levels of repeated noise can cause stress. Noise is an unavoidable stressor of daily modern life and a large segment of population is exposed to high levels of noise. Evidence also shows that repeated stress produces atrophy of dendrites and alterations in neurotransmitter levels (Naqvi, 2012). Exposure to noise constitutes a health risk. There is enough scientific facts that noise exposure can induce hearing impairment, hypertension and ischemic heart disease, annoyance, sleep disturbance (Passchier-Vermeer, 2000). There is growing evidence suggesting that noise induced peripheral hearing loss can also induce functional changes in the central auditory system (Sun, 2008) is not responsible only for temporary or permanent hearing loss, but can also induce transient or permanent tinnitus, loudness recruitment and hyperacusis as well as reported to decreases the immune functions by reducing natural killer cells (Kay, 1998). Uneven loud noise during pregnancy had a significant effect on both male and female offspring's, low weight birth, impaired cognition and post natal growth (Shankar, 1999).

Pregnancy:

Pregnancy is characterized by dynamic changes in multiple body systems resulting in increased basal oxygen consumption and in changes in energy substrate use by different organs including the feto placental unit. From early pregnancy the human placenta influences maternal homeostasis. Nitric oxide (NO) is also locally produced by the placenta and together with other reactive nitrogen species contributes to potential oxidative stress (Dotsch, 2001) While confirmation of a pregnancy is often exciting news, it can also be the beginning of a very stressful period in the lives of the parents to be. Stress also affects labour. The stress response has a profound effect on the female hormonal system and can, in some cases, inhibit contractions and prolong the process (Anderson, 


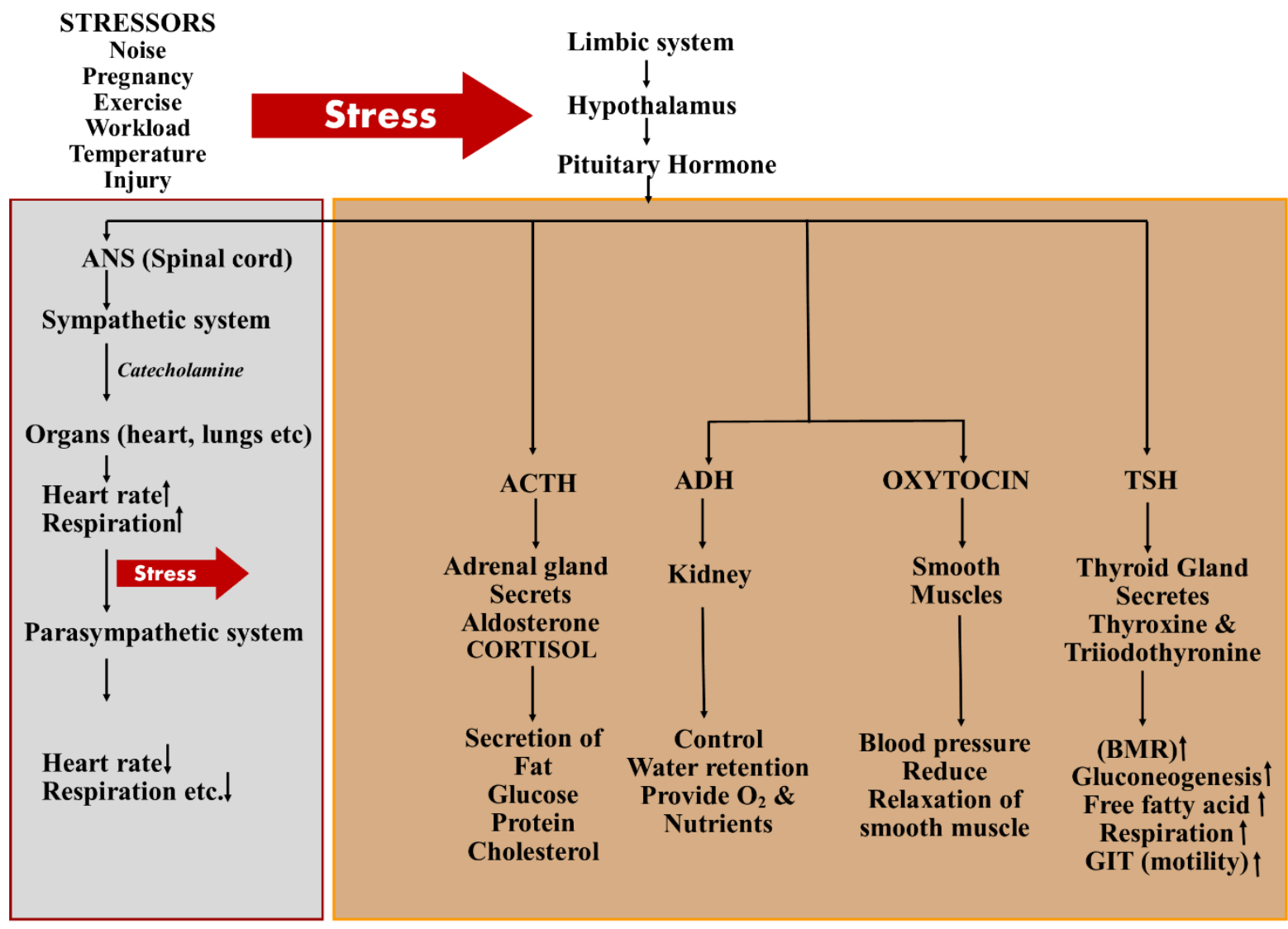

(a)

(b)

Figure : (a) acute pathway of stress: Upon perception of psycho physiological stress, the central stress response leads to the increases activity of body organs this pathway works very quickly and the effects are very short term. (b) chronic pathway of stress, the central stress response leads to the activation of the hypothalamic-pituitary-adrenal axis, which secretes (Adrenocorticotropic Hormone,-ACTH), Aldosterone, cortisol, Oxytocin, Antidiuretic Hormone-ADH (Vasopressin), Thyroxine \& Triiodothhyronine which alter the homeostasis of body .

2005). During pregnancy excessive physical stress may have negative influences on fetal development or a birth of low weight infant (March of Dimes, 2006). However normal stress hormones are necessary for normal fetal organ maturation and for preparing the fetus for extra uterine life (Challis, 2001; Hansen, 2000).There is an association between stress and cortisol secretion in human pregnancy. Recent findings in non-pregnant women show that a stress related hormone response is mainly found in evening cortisol levels (Powell, 2002). New studies found differences in the associations between chronic stress in early and late pregnancy and cortisol levels indicating that the response to chronic stress is dependent on the stage of the pregnancy (Obel, 2005).

\section{Exercise:}

Exercise is other stressor which lead to body in stress moreover is totally depends on duration and types of exercise aerobic and anaerobic. Aerobic exercises use the arm and leg muscles and give the heart and lungs a continuous workout. Anaerobic exercises build and tone muscles but are not as beneficial to the heart and lungs as aerobic activities. During anaerobic exercise your body builds up lactic acid, which causes uneasiness and fatigue at sustained levels. For this reason anaerobic exercise or high intensity exercise happens in short bursts. A number of studies have shown that psychological well-being can be influenced by physical activity/training. Physical activation is very much a stressor that affects the body's physiological stress systems (Doherty, 2000; Hawley, 2002). The release of adrenaline, noradrenaline and cortisol that occurs during physical training is similar to the release that occurs in connection with an acute psychological stress reaction (Borer, 2003). However the prevalent view is that regular physical activity of moderate to average intensity improves the function of the immune system and can reduce sensitivity to infections. However, hard or prolonged exercise in endurance sports can lead to immunosuppression and greater infection sensitivity (Sweden book) although, it appears that stressful stimuli differentially activate the HPA, it is not known whether a high responder to exercise stress will also be a high responder to psychological stress. This is an important issue because stress reactivity may have implications for health status. It appears that HPA reactivity at the two ends of the continuum, hypo and hyperreactivity, may influence an individual's susceptibility to developing various psychological, metabolic, inflammatory, and autoimmune disorders (Kirschbaum, 1995). Several studies have suggested that there is an increased risk of respiratory infections in subjects doing heavy exercise (Health, 1991). In literature that has been largely unconcerned with aerobic fitness, certain cardiovascular and biochemical changes have been reported during psychosocial stress, which involves little physical work (Singh, 1999).

Page $\mid 5$

(CAdvance Education Institute \& Research Centre-2014 


\section{Workload}

Employees continually reported that work load is a significant source of stress and they are typically feel tense or stressed out during the workday moreover of employees reporting at time of overwork they make a lot of mistakes at work (Galinsky, 2005; American Psychological Association, 2009). Physical work that sets high demands on main muscle groups, for example, in terms of manual materials handling, static-postural load, repetitive movements, and large output of force, is still the main element of many jobs (Pongian, 2002) Low back pain, a leading cause of disability in the industrialized world, is well recognized as having a multifactorial etiology. The main predictors of back pain include physical stress example, driving, prolonged lifting forceful or repetitive movements involving the back (Punnet, 1991). Workload as an aspect of objective reality of a job can be viewed as a direct source of stress, such as the frequency of any task or the nature of the task itself (Ezra, 2010). However physical workload has been identified within the frame of the sudden unexplained death syndrome (Gogh, 1993).

\section{Temperature}

Changing in temperature is a major cause of disturbing the body physiology. The nervous system is important in thermoregulation as the processes of homeostasis and temperature control are centered in the hypothalamus. The hypothalamus maintains the set point for body temperature through reflexes that cause vasodilatations and sweating when the body is too warm, or vasoconstriction and shivering when the body is too cold however, if this process occur for a long period of time it may cause physical stress.

\section{Injury}

The stress response to surgery, injury or trauma comprises a number of hormonal changes initiated by neuronal activation of HPA (axis). This is a part of the systemic reaction to injury which includes a wide range of endocrinological, immunological and hematological effects (Desborough, 2000). Physical stress is the force, or load, acting on a given area of tissue (Tipler, 1982). Tissues accommodate to physical stresses by altering their structure and composition to best meet the mechanical demands of routine loading. However Biological tissues exhibit responses to physical stress. Each response is predicted to occur within a defined range along a continuum of stress levels

Specific thresholds define the upper and lower stress levels for each characteristic tissue response by decreased stress tolerance (eg, atrophy), maintenance, increased stress tolerance (e.g. hypertrophy), injury, and death (Michael). Similar in the musculoskeletal and integumentary systems, excessive physical stress can injure tissues in the cardiovascular/pulmonary system. Mechanical stretch induced by high blood pressure is thought to be an initial event that leads to cardiac hypertrophy and eventual cardiac failure (Yamazaki, 1999). High blood pressure is an established risk factor for conditions such as stroke, myocardial infarction, and atherosclerotic disease (Taylor,1999).

\section{CONCLUSION:}

o Stress is the summated response of the biological reactions to any adverse stimulus, physical, mental, or emotional, internal or external, that tends to disturb the homeostasis of an organism (Erskine, 1972). Environment is an important contributor to life style. Environmental stresses from noise \& heat cause physical dysfunction in people (Schachter, 1962).

o Psychological symptoms are also consequences of many physical factors and can be defined as a set of interactions between the person and the environment.

o Physical Stress not only affects the individual's performance, work efficiency and group performance but also lost healthy shares in an increasingly competitive era, and may even jeopardize the survival of being in fast moving society (Kazmi, 2008).

o It is also essential to know the importance of physical workload affecting muscular work that can relate to productivity and work condition however the observations periods are needed to be selected so that they would be as demonstrative as possible (Yoopat, 2002).

o At the time of pregnancy excessive physical stress may have negative influences on fetal growth or a birth of low weight infant (March of Dimes, 2006).

o Noise disrupts the activity or balance of life and causes psycho-physiological changes.

o Variations in environmental Temperatures, physical activity and tissue exposures to injury are ubiquitous physical stress situations that also involve biochemical changes in body.

o The overall knowledge of physical stress is very relevant in the field of psychology, physiology and psychophysiology as it is not mostly considered to cause above mentioned effects. These day to day exposures to such stressors have the potentials to provoke acute as well as chronic stress conditions and need to be explored further.

\section{REFERENCES:}

- Ader R, Cohen N, Felten D (1995) Psychoneuroimmunology: interactions between the nervous system and the immune system. Lancet 345: 99-103.

- American Psychological Association. (2009).Stress in America 2009.Retrieved from http://www.apa.org/news/press/releases/stress-execsummary.pdf

- Anderson, R. (2005). Stress and pregnancy. Journal-royal society for the promotion of health, 125(5), 215.

- $\quad$ Anita Singh, John S. Petrides, Philip W. Gold, George P. Chrousos, \& Patricia A. Deuster (1999) Differential Hypothalamic-Pituitary-Adrenal Axis Reactivity to Psychological and Physical Stress, The Journal of Clinical Endocrinology \& Metabolism, Vol. 84 (6),1944-1948.

- Atkinson R. L. (1996). Hilgard's introduction to psychology (Ch. 2, Glossary: Epinephrine, Endocrine system, Fight or Flight, Hormone, Stress).

- Borer, K. T. (2003). Exercise endocrinology. Human Kinetics.

- $\quad$ Challis, J.R., Sloboda, D., Matthews, S.G., Holloway, A., Alfaidy, N., Patel, F.A., Whittle, W., Fraser, M., Moss, T.J., Newnham, J. (2001). The fetal placental hypothalamicpituitary-adrenal (HPA) axis, parturition and post natal health. Mol. Cell Endocrinol. (185), 135-144.

- Crandon AJ. Maternal anxiety and obstetric complications. J Psychosoni Res 1979:23:109-11.

- Doherty, T.J. (2000). Effects of short-term training on physiologic properties of human motor units. Can J Appl Physiol (25), 194-203.

Page $\mid 6$ 
- $\quad$ Stotland, E., \& Pendleton, M. (1989). Workload, stress, and strain among police officers. Behavioral Medicine, 15(1), 517.

- $\quad$ Galinsky, E., Bond, J. T., Kim, S. S., Backon, L., Brownfield, E., \& Sakai, K. (2005). Overwork in America: When the way we work becomes too much. Families and Work Institute. Retrieved

from http://familiesandwork.org/site/research/summary/overwork2 005summ.pdf

- Gogh, K.T. (1990). Sudden unexplained death syndrome among Thai workers in Singapore. Paper presented at the National Epidemiology Seminar, Bangkok, Thailand.

- Grant, J. E., Brewer, J. A., \& Potenza, M. N. (2006). The Neurobiology of Substance and Behavioral Addictions (2006). CNS spectr, 11(12), 924-930.

- Hansen, D., Lou, H.C., Olsen, J. (2000). Serious life events and congenital malformations: a national study with complete follow-up. Lancet (356), 875-880.

- Hawley, J.A. (2002). Adaptations of skeletal muscle to prolonged, intense endurance training. Clin Exp Pharmacol Physiol 29:218-22.

- Heath, G. W., Ford, E. S., Craven, T. E., Macera, C. A., Jackson, K. L., \& Pate, R. R. (1991). Exercise and the incidence of upper respiratory tract infections. Medicine and science in sports and exercise, 23(2), 152-157.

- $\quad$ Desborough, J.P. (2000), The stress to trauma and surgery,Br J Anaesth , 85 (1), 109- 117.

- $\quad$ Kay, G., Tarcic, N., Poltyrev, T., \& Weinstock, M. (1998). Prenatal stress depresses immune function in rats. Physiology \& behavior, 63(3), 397-402.

- $\quad$ Kirschbaum, C., Prussner, J. C., Stone, A. A., Federenko, I., Gaab, J., Lintz, D., \& Hellhammer, D. H. (1995). Persistent high cortisol responses to repeated psychological stress in a subpopulation of healthy men. Psychosomatic medicine, 57(5), 468-474

- $\quad$ Lazarus, R. S., \& Folkman, S. (1986). Cognitive theories of stress and the issue of circularity. In Dynamics of stress (pp.63-80). Springer US

- March of Dimes. (2006). Preterm labor: Stress and prematurity. Retrieved January 20, 2014, fromhttps://www.marchofdimes.com/pregnancy/pretermlabor _stress.html

- $\quad$ Mueller, M. J., \& Maluf, K. S. (2002). Tissue adaptation to physical stress: a proposed "Physical Stress Theory" to guide physical therapist practice, education, and research. Physical Therapy, 82(4), 383-403.

- $\quad$ Miller, G. E., Chen, E., \& Zhou, E. S. (2007). If it goes up, must it come down? Chronic stress and the hypothalamicpituitary-adrenocortical axis in humans. Psychological bulletin, 133(1), 25.

- $\quad$ Naqvi, F., Haider, S., Batool, Z., Perveen, T., \& Haleem, D. J. (2012). Sub-chronic exposure to noise affects locomotor activity and produces anxiogenic and depressive like behavior in rats. Pharmacol Rep, 64(1), 64-69.

- Obel, C., Hedegaard, M., Henriksen, T. B., Secher, N. J., Olsen, J., \& Levine, S. (2005). Stress and salivary cortisol during pregnancy.Psychoneuroendocrinology, 30(7), $647-$ 656.

Page 17

(C)Advance Education Institute \& Research Centre-2014
- Passchier-Vermeer, W., \& Passchier, W. F. (2000). Noise exposure and public health. Environmental health perspectives, 108(Suppl 1), 123.

- Yoopat, P., Toicharoen, P., Glinsukon, T., Vanwonterghem, K., \& Louhevaara, V. (2002). Ergonomics in practice: physical workload and heat stress in Thailand. International Journal of Occupational Safety and Ergonomics, 8(1), 83-93.

- $\quad$ Powell, L.H., Lovallo, W.R., Matthews, K.A., Meyer, P., Midgley, A.R., Baum, A., Stone, A.A., Underwood, L., McCann, J.J., Janikula, H.K., Ory, M.G., (2002). Physiologic markers of chronic stress in premenopausal, middle-aged women. Psychosom. Med. (64), 502-509.

- $\quad$ Punnett, L., Fine, L. J., Keyserling, W. M., Herrin, G. D., \& Chaffin, D. B. (1991). Back disorders and nonneutral trunk postures of automobile assembly workers. Scandinavian journal of work, environment \& health, 337-346.

- Shankar, N., Awasthy, N., Mago, H., \& Tandon, O. P (1999). Analgesic effect of environmental noise: a possible stress response in rats. Indian journal of physiology and pharmacology, 43(3), 337-346.

- $\quad$ Singh, A., Petrides, J. S., Gold, P. W., Chrousos, G. P., \& Deuster, P. A. (1999). Differential hypothalamic-pituitaryadrenal axis reactivity to psychological and physical stress. Journal of Clinical Endocrinology \& Metabolism, 84(6), 1944-1948.

- $\quad$ Sun, W., Zhang, L., Lu, J., Yang, G., Laundrie, E., \& Salvi, R. (2008). Noise exposure-induced enhancement of auditory cortex response and changes in gene expression. Neuroscience, 156(2), 374-380.

- $\quad$ Sung, D. Y., Kaplan, F., Lee, K. J., \& Guy, C. L. (2003). Acquired tolerance to temperature extremes. Trends in plant science, 8(4), 179-187.

- Sweden book (2010). Physical Activity in the Prevention and Treatment of Disease professional associations for physical activity. Retrieved from http://www.fyss.se/wpcontent/uploads/2011/02/fyss 2010 english.pdf

- $\quad$ Syed, Z., A.(2013), Chronic Stress; Leading Cause of IllBeing, Escalating Research: A quarterly Science magazine, Volume 2 (4),18-21.

- $\quad$ Taylor, W. R. (1998). Mechanical deformation of the arterial wall in hypertension: a mechanism for vascular pathology. The American journal of the medical sciences, 316(3), 156161.

- $\quad$ Tipler, P.A. (1982). Physics. 2nd ed. New York, NY: Worth Publishers

- $\quad$ Yamazaki, T., Komuro, I., Shiojima, I., \& Yazaki, Y. (1999). The molecular mechanism of cardiac hypertrophy and failure. Annals of the New York Academy of Sciences, 874(1), 38-48.

- $\quad$ Preventing heat stress (2007) WORK SAFE BC publications.

- $\quad$ Sadaf, A. \& Shamoon, N. (2013). Sorts and Sources of Stress in Pakistan; A Comprehensive Outlook, International journal of endorsing health science research. (1), 1.

- $\quad$ Stevens, R. E., Loudon, D. L., Yow, D. A., Humphrey, J. H., \& Bowden, W. W. (2013). Stress in college athletics: Causes, consequences, coping. Routledge.

- $\quad$ Syed, Z. A., Sadaf. A., \& Shamoon, N. (2014). Introduction to physical Stress, Grasping Physical Stress; A Step towards Your Health (pp 6-9). 
- Yoopat, P. O. N. G. J. A. N. (2002). Cardiorespiratory capacity and strain of blue-collar workers in Thailand. Kuopio University Publications D. Med Sci, 281, 1 Á85.

- $\quad$ Erskine, H. (1972). The polls: Pollution and its costs. Public Opinion Quarterly, 120-135.

- Schachter, S., \& Singer, J. (1962). Cognitive, social, and physiological determinants of emotional state. Psychological review, 69(5), 379 .

- $\quad$ Kazmi, R., Amjad, S., \& Khan, D. (2008). Occupational stress and its effect on job performance-A case study of medical house officers of district Abbottabad. J Ayub Med Coll Abbottabad, 20(3), 135-139. 